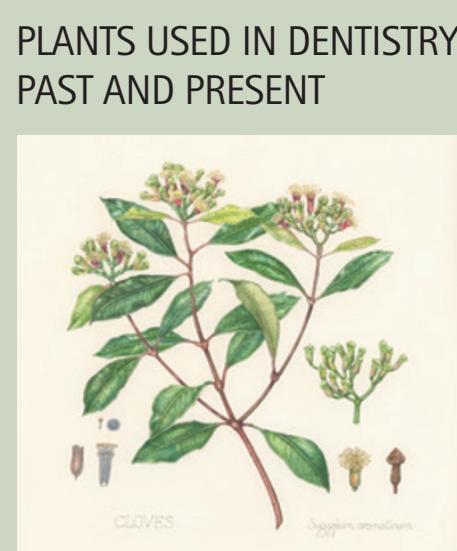

This issue of the $B D J$ displays the first cover in a brand new series. The theme for Volume 218 is 'Plants and trees in dentistry's past and present'.

The first cover, for issue 1 , is an original illustration of cloves, created by artist Liz Pepperell. Liz is creating all 12 covers in the style of traditional botanical drawings.

Cloves are the aromatic flower buds of a tree in the Myrtaceae family, Syzygium aromaticum. In the past cloves were used as a remedy to ease the pain of toothache. Clove oil has a local anaesthetic effect and temporarily numbs and relieves pain. It is used in the preparation of some toothpastes and in Clovacaine solution, a local anaesthetic used in oral ulceration and inflammation. Eugenol, which is extracted from essential oils including clove oil, is also mixed with zinc oxide to form temporary tooth restorations.

Artist Liz Pepperell lives in Devon and loves visiting gardens such as Nymans in West Sussex and Knightshayes Court in Devon, which inspire the plants and flowers that she paints. She works in watercolours, pencil and ink, in a style traditional in the world of botanical and natural history illustration.

When approaching an illustration, Liz first sketches loose ideas in pencil and ink on tracing paper, scrubbing out and redrawing as she goes. Whenever possible she works from life.

Future covers in Volume 218 will feature original illustrations of licorice root, miswak, myrrh, neem tree and tea tree.

\section{FROM THE ARCHIVE}

\section{BLOOD AND THUNDER DENTISTRY}

$\mathrm{R}$ etired dentist Alan G. Green contacted the $B D J$ having seen the special 'From the archive' featuring 97-year-old Sydney Grennan (Grubs, fire bombs, India and a paper in the British Dental Journal; BDJ 2014; 217: 216-217).

Captain Alan G. Green LDS RADC published the article $A$ survey of the dental condition of 19-yearold youths in the BDJ on 21 April 1953 in Volume 94 (pictured). The survey examined 500 youths called up for service with the Army and selected as potential vehicle drivers. The following text is an extract from the article, under the heading 'DISCUSSION':

It would seem that the dental condition of those surveyed is most unsatisfactory and that many had not received treatment through lack of initiative, understanding, or opportunity.

There is overall a dislike of dentures which is part based on parental experience.

An average DMF index of 8 has been obtained. [...] It is strongly felt that the group possessed little, if any, understanding of matters dental, and it is hoped that more is now being done in the schools to emphasise that pain is not the only criterion of the necessity for dental treatment. Very much the same opinion was formed by Palmer (1950) who studied statistically dental conditions in New York. He stated that "Most patients do not visit the dentist unless they are in pain, have a swollen face or a broken tooth."

A frequent reason given for the refusal of dental treatment was "I had some fillings done some time ago, but they fell out soon after - so I don't believe in them."

Alan also sent the $B D J$ an account of his student, hospital and army days which we are pleased to share with readers, as follows:

Tlived in Liverpool throughout the war and was accustomed to the bomb damage. In 1945, at the tender age of 17, I became a naive dental student. With so much housing stock destroyed, student accommodation was in very short supply and living at home, commuting to uni, was the order of the day. Kids living around the university were often shoeless. There was a different definition of poverty!

The quad was covered by a pile of coal, Liverpool's emergency supply for homes and ships. Dissection in winter was a problem as the dissecting room's windows had been blown out and not replaced. Hats, overcoats and any warm clothing was the order of the day. The male toilet had a large container for urine, donations requested by Biochemistry. Unfortunately, a stirrup pump [used for tackling incendiary bomb fires] was located nearby so a visit to the 'loo' was extremely hazardous. We were fortunate to have an early

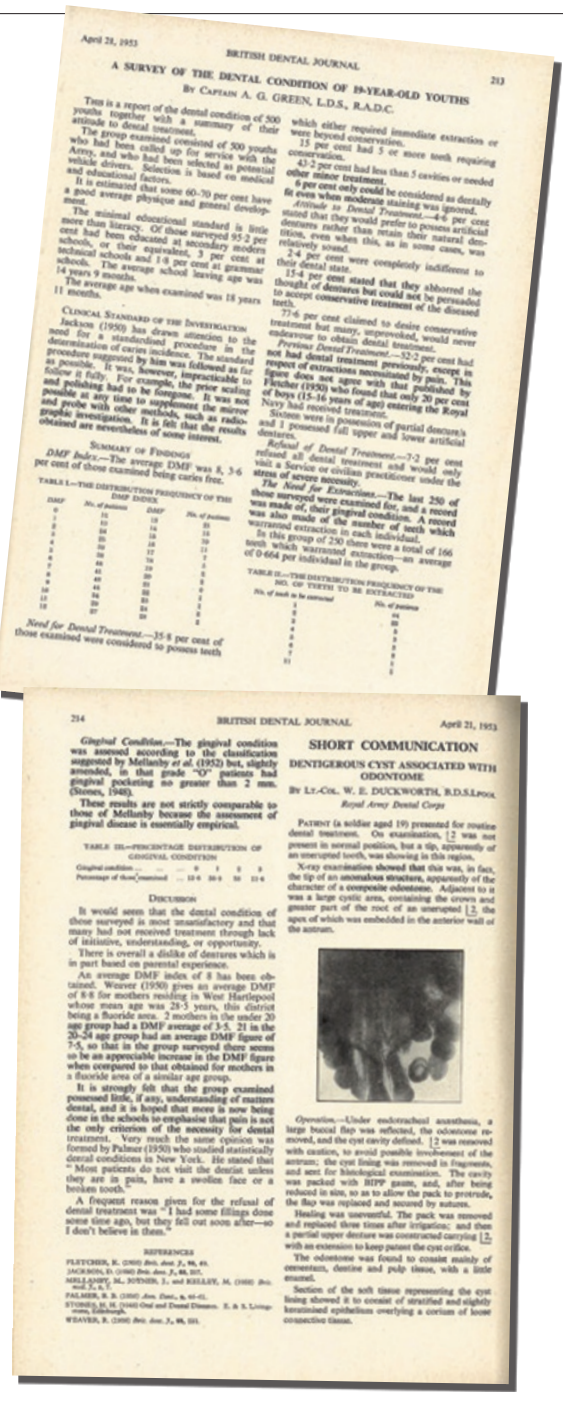

supply of the miracle LA, xylocaine, but antibiotics were not available and trench mouth prevalent at the time was treated by the archaic chromic acid and hydrogen peroxide method. 'Cons' had one functioning hot water steriliser which never reached boiling due to the frequent instrument exchanges. For the first six months we had to use foot engines. I was never sure whether it was worse for the patients or the student operator. In prosthetics 'compo' was used for some impressions. It went from patient to lab and back to another patient. Surprisingly, we never noticed cross infection problems!

The class of 1945 were mostly from school but the class of " 46 was very different. The ex-servicemen were those with the longest war service, veterans of bombing raids, the Battle of the Atlantic and every aspect of the war. One baby-faced, apparent school leaver turned out to be a retired major whose last posting had been the Inspector of Brothels in Cairo. We had an eclectic student mix! 